\title{
KINERJA POMPA JET EJECTOR DENGAN MODIFIKASI HELMHOLTZ RESONATOR PADA PIPA NORMAL SHOCK
}

\author{
Mesak F. Noya* \\ Program Studi Teknik Sistem Perkapalan, Fakultas Teknik, Universitas Pattimura, Ambon,Indonesia \\ Rusdy Rumeon \\ Program Studi Teknik Sistem Perkapalan, Fakultas Teknik, Universitas Pattimura, Ambon,Indonesia \\ P. W. Tetelepta \\ Program Studi Teknik Sistem Perkapalan, Fakultas Teknik, Universitas Pattimura, Ambon,Indonesia
}

\author{
Abdul Hadi \\ Program Studi Teknik Sistem Perkapalan, Fakultas Teknik, Universitas Pattimura, Ambon,Indonesia \\ *E-mail korespondensi: mesakfrits@gmail.com
}

\begin{abstract}
ABSTRAK
Setiap fluida yang mengalir selalu memiliki bunyi dengan intensitas dan frekwensi tertentu di dalam atau diluar ambang batas audio. Sifat akustik dari aliran fluida ini menjadi ide untuk memodifikasi normal shock diffuser dari suatu sistem fluida dengan menerapkan helmholtz resonator sebagai pengganti normal shock diffuser dengan menggabungkan dua pompa yang di aliri fluida, yaitu pompa sentrifugal tekanan rendah berkapasitas tinggi dan pompa injeksi tekanan tinggi berkapasitas rendah. Penelitian ini bertujuan untuk menentukan berapa besar pengaruh variasi jumlah pipa kapiler helmholtz resonator terhadap kinerja aliran fluida hidrolik booster-jet ejector pump. Penelitian ini bersifat eksperimental, dengan menerapkan sensor magneto flow meter arduino mega untuk mengukur kapasitas aliran fluida. Hasil penelitian ini menunjukan daya terbesar berada pada helmholtz resonator dengan jumlah 4 pipa kapiler yaitu sebesar 170,914353 Watt. Disimpulkan bahwa kinerja pompa jet-ejector mengalami peningkatan sebesar 36\% dari daya sebesar 125Watt sebelum modifikasi.
\end{abstract}

Kata Kunci : Booster Jet Ejector, Resonator Helmholtz, Normal Shock

\begin{abstract}
Every fluid that flows always has a sound with a certain intensity and frequency, within or outside the audio threshold. The acoustic properties of this fluid flow became the idea to modify the normal shock diffuser of a fluid system by applying a Helmholtz resonator as a substitute for the normal shock diffuser by combining two pumps that are fed with fluid entering through a high-capacity low-pressure centrifugal pump and the other pump namely high pressure -low capacity injection pump. This study aims to determine how much the variation in the number of Helmholtz resonator capillaries towards performance of the hydraulic fluid flow of the boosterjet ejector pump. This research is experimental, by applying the arduino mega magneto flow meter sensor to measure the fluid flow capacity. The results of this study show that the greatest power is in the helmholtz resonator with a total of 4 capillary pipes, which is 170.914353 Watt. It is concluded that the performance of the jet-ejector pump has increased by $36 \%$ from the power of 125 Watt before modification.
\end{abstract}

Keywords: Booster Jet Ejector, Helmholtz Resonator, Normal Shock 


\section{PENDAHULUAN}

Dalam bidang kajian tentang mekanika fluida, sebagaimana dikemukakan oleh Brenner (1994) dan Fox et al. (2008), bahwa setiap fluida yang mengalir selalu memiliki bunyi dengan intensitas dan frekuensi tertentu di dalam atau di luar ambang batas audio. Sifat akustik dari aliran fluida ini menjadi ide untuk memodifikasi normal shock diffuser dengan Helmholtz resonator pada suatu vaccum ejector yang dapat di operasikan sebagai booster ejector pump (pompa booster) untuk meningkatkan kecepatan aliran fluida, tekanan, dan daya alir. Dengan menggabungkan dua pompa yang dialiri fluida yang masuk melalui pompa sentrifugal bertekanan rendah berkapasitas tinggi dengan pompa injeksi bertekan tinggi berkapasitas rendah. Proses aplikasi helmholtz resonator dikemukan oleh Hersch dan Wolker dengan memvariasikan helmholtz resonator pada inlet manifold untuk mengontrol kondisi aliran udara. Selanjutnya, Bertoluzzi et al. (1998) meneliti tentang penggunaan resonator untuk mengontrol efisiensi volumetrik dari sebuah mesin kemudian Yunita et al (2019), meneliti tentang pengaruh diameter leher helmhohz resonator pada alat pemanen energi akustik (acoustic energy harvester) terhadap daya listrik yang di hasilkan, menyimpulkan bahwa semakin besar diameter leher menghasilkan daya listrik yang semakin besar.

Dalam penelitian ini, helmholtz resonator digunakan untuk meningkatkan kecepatan dan tekanan aliran fluida dan daya alir setelah diffuser. Resonator ini berbentuk sirkular yang dilengkapi dengan variasi lima pipa kapiler dengan ukuran diameter dan panjang yang sama. Resonator ini dipasang pada penampang melintang pipa utama (grazing line) sebagai pengganti pipa normal shock diffuser. Dengan variasi jumlah pipa kapiler sebanyak lima perlakuan diharapkan kinerja pompa jet ejector dapat meningkat.

\section{BAHAN DAN METODE}

Penelitian ini dilakukan dengan pendekatan eksperimen pada Laboratorium Pengujian Mesin Fakultas Teknik Universitas Pattimura. Penelitian dilakukan untuk melihat pengaruh variasi jumlah pipa kapiler helmholtz resonator terhadap daya alir hidrolik booster jet ejector pump (Xioafeng, 2013).

\section{a. Bahan}

\section{Helmholtz, Resonator}

Helmholtz resonator adalah peristiwa resonansi fluida dalam satu rongga. Resonator tersebut terdiri dari suatu badan yang berbentuk bola dengan satu volume fluida dengan sebuah leher. Nama ini berasal dari perangkat yang diciptakan pada tahun 1850-an oleh Hermann Von Helmholtz (Helmholtz, Hermann Ludwig Ferdinand Von, 1821-1894) yang digunakan untuk menunjukkan tinggi dari berbagai nada.

Prinsip kerja helmholtz resonator adalah pada saat gelombang menabrak ruang, maka sebagian akan diteruskan ke dalam ruangan dan sebagian akan dipantulkan. Panjang dari ruang resonator ini harus dihitung sehingga gelombang pantulan meninggalkan ruang resonator harus tepat pada saat gelombang suara berikutnya datang ke ruang resonator (Louhenapessy, 2017)

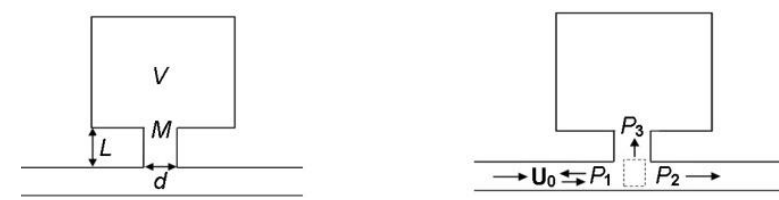

Gambar 1. Helmholtz Resonator dan Tekanan aliran

Menurut Xiang (2013), helmholtz resonator seperti pada Gambar 1 sisi cabang dipasang pada sisi dinding dari saluran jauh dan gelombang pesawat menjalar sepanjang saluran. Dengan daerah penampang saluran adalah $\mathrm{V}$, maka yang mengalir dari saluran adalah $\mathrm{U}_{0}$. Daerah titik menunjukkan diskontinuitas tekanan daerah karena aliran rata-rata pada tekanan hulu adalah P1 dan tekanan hilir adalah P2. Tekanan pada leher helmholtz resonator adalah P3 dan dianggap sama dengan tekanan hulu P1 di persimpangan. 


\section{Ejector Pump}

Kolmogorov (1949) menyatakanejector adalah alat untuk mengeluarkan gas atau zat cair dari ruangan dengan menggunakan aliran zat cair atau uap lain yang berkecepatan tinggi. Ejector dapat merupakan jenis kompresor, dalam hal ini tekanan tinggi yang dialirkan melalui sebuah nozzle yang mengakibatkan pengembangan dan menyebabkan timbulnya vacum.

\section{Formulasi Pengukuran Eksperimen Aliran Fluida}

Harga cepat rambat bunyi aliran fluida dari system fluida, a dapat dihitung dengan menggunakan persamaan Joukowsky water Hammer seperti dikemukakan oleh Brennen (1994)

$$
\begin{aligned}
& a=\left[\rho_{f}\left(\frac{1}{K_{f}}+\frac{D}{E_{p} \delta_{p}}\right)\right]^{-\frac{1}{2}} \\
& a_{\infty}=\left[\frac{k_{f}}{\rho_{f}}\right]^{-\frac{1}{2}} \\
& a_{s}=\left[\left(\frac{1}{a_{\infty}^{2}}+\frac{\rho_{f} D_{s}}{E_{p s} \delta_{p s}}\right)\right]^{-\frac{1}{2}} \\
& a_{o}=\left[\left(\frac{1}{a_{\infty}^{2}}+\frac{\rho_{f} D_{o}}{E_{p o} \delta_{p o}}\right)\right]^{-\frac{1}{2}}
\end{aligned}
$$

dimana $a_{o}=$ Cepat rambat bunyi $(\mathrm{m} / \mathrm{s}), a_{\infty}=$ Cepat rambat bunyi aliran dalam pipa $(\mathrm{m} / \mathrm{s}), \rho_{f}=$ Densitas air $(\mathrm{kg} / \mathrm{m} 3), D_{o}=$ Diameter output $(\mathrm{cm}), E_{p o}=$ Modulus elastisitas pipa $(\mathrm{Pa}), \delta_{p o}=$ Tebal pipa $(\mathrm{cm})$, dan $k_{f}=$ Modulus Bulk $(\mathrm{Pa})$.

Dari sifat kontinuitas aliran dapat dipertimbangkan bahwa:

$$
\begin{aligned}
& A_{o} \cdot V_{o}=A_{S} \cdot v_{S} \text { Atau } v_{o}=\frac{A_{S}}{A_{o}} \cdot v_{S} \\
& A_{o} \cdot v_{o}=A_{S} \cdot v_{S} \\
& v_{S}=\frac{Q_{S}}{A S} \\
& v_{O}=\frac{A_{S}}{A o} \cdot v_{S}
\end{aligned}
$$

dimana $v_{s}=$ Kecepatan profil sensor $(\mathrm{m} / \mathrm{s}), v_{o}=$ Kecepatan profil output $(\mathrm{m} / \mathrm{s}), Q_{s}=$ Debit Aliran (m3/s), $A_{S}=$ Luas Penampang sensor (m), dan $A o=$ Luas penampang output (m). Sedangkan dari sifat kompresibilitas aliran fluida pada kondisi isotermal dipenuhi tekanan diferensial aliran fluida yaitu:

$$
\begin{aligned}
& p_{S}=\frac{k_{f}}{a_{S}} \cdot v_{S} \\
& \text { dan } \\
& p_{o}=\frac{k_{f}}{a_{o}} \cdot v_{o}
\end{aligned}
$$

dimana $p_{S}=$ Tekanan diferensial sensor $(\mathrm{Pa}), p_{o}=$ Tekanan diferensial output $(\mathrm{Pa}), k_{f}=$ Modulus Bulk $(\mathrm{Pa}), a_{o}=$ Cepat rambat bunyi $(\mathrm{m} / \mathrm{s}), a_{s}=$ Cepat rambat sensor $(\mathrm{m} / \mathrm{s})$, dan $v_{o}=$ Kecepatan profil output $(\mathrm{m} / \mathrm{s})$. Sehingga diperoleh daya output aliran fluida N, yaitu:

$$
N_{o}=A_{o} p_{o} v_{o}
$$

dimana $N_{o}=$ Daya alir output $(\mathrm{W}), A_{o}=$ Luas penampang output $(\mathrm{m}), p_{o}=$ Tekanan diferensial output $(\mathrm{Pa})$, dan $v_{o}=$ Kecepatan profil output $(\mathrm{m} / \mathrm{s})$.

Selanjutnya diasumsikan bahwa noise dari sensor flow meter dengan margin error $\pm 5 \%$ adalah relatif kecil atau secara praktis diabaikan. Dengan demikian harga rata-rata debit $Q_{s}$ atau kecepatan rata-rata profil $v_{s}$ aliran fluida pengukuran adalah bersifat random dan diperhitungkan secara recursive sample.

\section{Spesifikasi Arduino Mega 2560}

Board Arduino Mega 2560 adalah sebuah Board Arduino yang menggunakan ic Mikrokontroler ATmega 2560.Board ini memiliki Pin I/O yang relatif banyak, 54 digital Input / Output,15 buah di antaranya dapat digunakan sebagai output PWM, 16 buah analog Input, 4 
UART. Arduino Mega 2560 dilengkapi kristal 16. Mhz Untuk penggunaan relatif sederhana tinggal menghubungkan power dari USB ke PC/ Laptop atau melalui Jack DC pakai adaptor 712 VDC (Arduino.com, 2016).

Untuk lebih jelasnya dapat dilihat dari spesifikasi Arduino Mega 2560 di bawah ini: Mikrokontroler Atmega 2560, Tegangan Operasional 5V, Tegangan Input (rekomendasi) antara 7-12V , Tegangan Input (limit) antara 6-20V, 54 Pin Digital I/O (Of which 15 provide PWM output), 16 Pin Analog Input, Arus DC per Pin I/O $20 \mathrm{~mA}$, Arus DC untuk Pin $3.3 \mathrm{~V}$ sebesar 50 $\mathrm{mA}$, Memori Flash $256 \mathrm{~KB}$ dimana 8 KB digunakan oleh bootloader, SRAM 8 KB, EEPROM 4 KB, Clock Speed 16 MHz,LED_BUILTIN 13, Panjang 101,52 mm, Lebar 53,3 mm, Berat 37 gram.

\section{Spesifikasi Sensor-Water Flow Meter}

Water Flow Meter 1 - 30L / MIN adalah sensor aliran/ debit udara yang dapat diaplikasikan untuk pengukuran debit aliran air dan sejenisnya. Sangat cocok untuk proyek dengan Arduino.

\section{b. Metodologi}

Penelitian ini dilakukan pada Laboratorium Pengujian Mesin Fakultas Teknik Universitas Pattimura dengan mengukur kapasitas aliran fluida diffuser secara eksperimental untuk kondisi awal sebelum perlakuan dan dengan perlakuan ke-1 sampai dengan ke-5. Untuk setiap variasi perlakuan, ukuran diameter dan panjang pipa kapiler adalah sama. Selanjutnya secara teoritis dilakukan perhitungan daya alir fluida setelah diffuser.

\section{Skema Gambar Peralatan Penelitian}

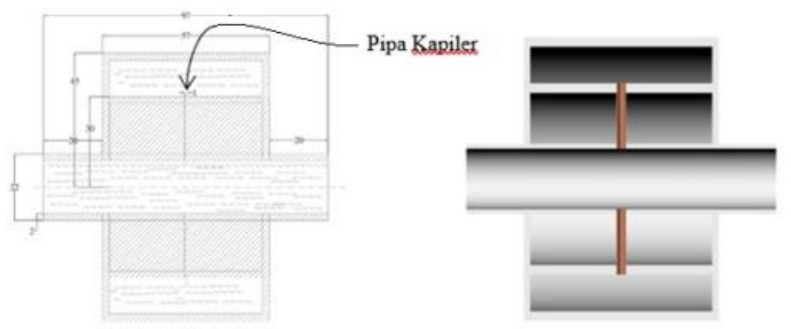

Gambar 2. Helmholtz Resonator

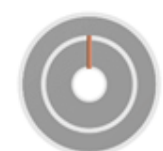

(a)

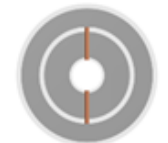

(b)

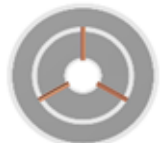

(c)

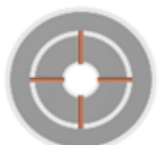

(d)

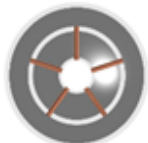

(e)

Gambar 3. Posisi variasi jumlah pipa kapiler Helmholtz

(a) Jumlah 1 pipa kapiler, (b) Jumlah 2 pipa kapiler, (c) Jumlah 3 pipa kapiler,

(d) Jumlah 4 pipa kapiler, (e) Jumlah 5 pipa kapiler

\section{Prosedur Penelitian}

Instalasi peralatan sesuai rancangan penelitian (Gambar 4). Dengan elektromotor 3 phase, daya 3 Hp putaran $2480 \mathrm{rpm}$ dan injection pump, fluida masuk melalui centrifugal pump dan spray duster menuju ejector, melalui rongga kemudian masuk ke helmholtz resonator dan keluar melalui diffuser. Alat penelitian diuji untuk mengetahui tidak ada lagi kehilangan di setiap proses, yaitu tidak adanya kebocoran di pipa-pipa dan nozzle pengabut dengan baik. Proses pengukuran dilakukan dengan menggunakan Sensor Flowmeter dan Arduino Mega 2560, dan dipastikan alat uji berada dalam kondisi telah dikalibrasi dengan baik. Pengambilan data dilakukanterhadap 5 perlakuan,dengan 5 kali pengulangan untuk setiap variasi jumlah pipa kapiler helmholtz resonator.Selanjutnya pergantian helmholtz resonator untuk setiap variasi dengan jumlah pipa kapiler yang berbeda. 


\section{Mekanisme Penelitian}

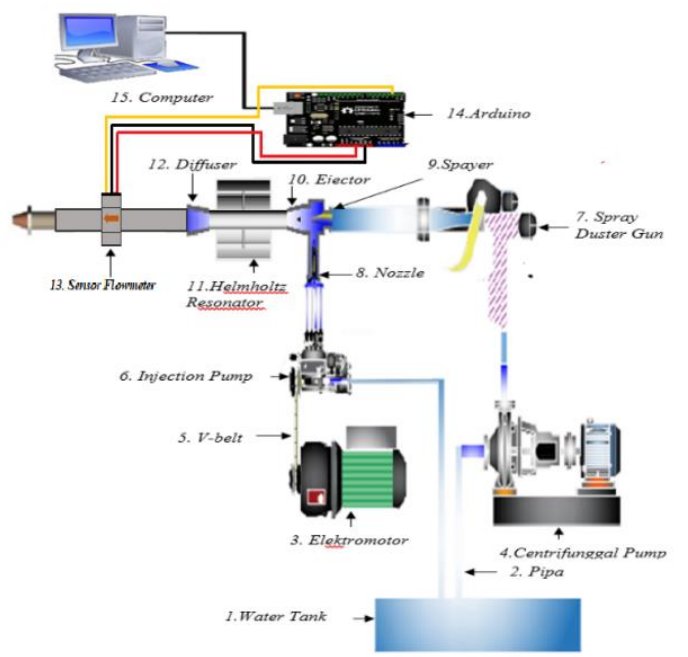

Gambar 4. Rancangan Penelitian

\section{Teknik Akuisisi dan Pengambilan Data}

Pengambilan data dilakukan pada setiap perlakuan dengan 5 kali pengulangan, data diperoleh dalam bentuk debit aliran fluida (Q) setelah electromotor dan injection pump dijalankan bersama dengan centrifugal pump yang terhubung langsung dengan ejector masing masing posisinya berada pada primary fluid dan secondary fluid, setelah aliran fluida tercampur di dalam bagian mixing chamber ejector aliran fluida melewati helmholtz resonator dan selanjutnya aliran fluida keluar pipa output diffuser. Proses pengukuran dengan menggunakan sensor flowmeter, direkam oleh Arduino Mega 2560, kemudian muncul di komputer pada aplikasi arduino uno R3, dan pada proses pengolahan data menggunakan microsoft excel.

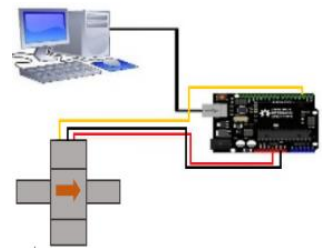

Gambar 5. Instrumen pengukuran kecepatan aliran fluida Hidrolik dalam pipa dengan Sensor Flow

$$
\text { Meter }
$$

\section{HASIL DAN PEMBAHASAN}

Setelah semua tahapan dilakukan sesuai mekanisme penelitian dan tahapan prosedur penelitian, dengan menggunakan Sensor Flow Meter, Arduino Mega, dan Computer, maka diperoleh data penelitian berupa kecepatan aliran(Flow Rate), tekanan diferensial aliran (Current Liquid Flowing), dan daya aliran (Output Liquid Quantity) dapat dilihat pada Tabel 1.

Tabel 1. Hasil Pengolahan data untuk 5 pipa kapiler di tiap pengulangan untuk menentukan kecepatan,tekanan dan Daya rata-rata aliran fluida Helmholtz resonator

\begin{tabular}{|c|c|c|c|c|c|c|c|c|c|c|c|c|c|c|c|c|c|c|c|}
\hline \multirow{2}{*}{$\begin{array}{l}\text { Jumlah } \\
\text { Pipa } \\
\text { kapiler }\end{array}$} & \multirow{2}{*}{$\begin{array}{l}\text { Waktu pengukuran } \\
\text { aliran air }(\mathrm{sec})\end{array}$} & \multicolumn{6}{|c|}{$\begin{array}{l}\text { Kecepatan aliran fluida } \\
\text { pada pipa output }(\mathrm{m} / \mathrm{s})\end{array}$} & \multicolumn{6}{|c|}{$\begin{array}{l}\text { Tekanan aliran fluida } \\
\text { pada pipa output }(\mathrm{Pa})\end{array}$} & \multicolumn{6}{|c|}{$\begin{array}{c}\text { Daya alir fluida } \\
\text { pada pipa output }(\mathrm{W})\end{array}$} \\
\hline & & 1 & 2 & 3 & 4 & 5 & Nilai & 1 & 2 & 3 & 4 & 5 & Nilai & 1 & 2 & 3 & 4 & 5 & Nilai \\
\hline 1 & $\begin{array}{l}1,16,17,35,39 \\
40,42,44,48\end{array}$ & & & & $\checkmark$ & & 0,647924 & & & & $\sqrt{ }$ & & 930373 & & & & $\sqrt{ }$ & & 170,914353 \\
\hline 2 & $15,40,43,44$ & $\checkmark$ & & & & & 0,647924 & $\checkmark$ & & & & & 930373 & $\checkmark$ & & & & & 170,914353 \\
\hline 3 & $21,34,40,44,48$ & & & & $\checkmark$ & & 0,647924 & & & & $\checkmark$ & & 930373 & & & & $\checkmark$ & & 170,914353 \\
\hline 4 & $\begin{array}{l}4,9,14,24,29,35 \\
41,42,43,4547\end{array}$ & & & $\checkmark$ & & & 0,647924 & & & $\checkmark$ & & & 930373 & & & $\checkmark$ & & & 170,914353 \\
\hline 5 & 26,48 & $\checkmark$ & & & & & 0,647924 & $\checkmark$ & & & & & 930373 & $\checkmark$ & & & & & 170,914353 \\
\hline
\end{tabular}


a. Kecepatan aliran, tekanan diferensial aliran, dan daya aliran untuk percobaan 1 pipa kapiler

Untuk percobaan dengan 1 pipa kapiler helmholtz resonator, pada waktu 1,16, 17, 35, 39, 40, 42, 44, dan 48 det, kecepatan aliran sebesar 0,647924 m/s (Gambar 6.a), dan tekanan diferensial aliransebesar 930373,00 Pa, (Gambar 6.b). Sementara, daya aliran sebesar 170,91353 W, tercapai pada pengulangan ke-4 (Gambar 6.c).

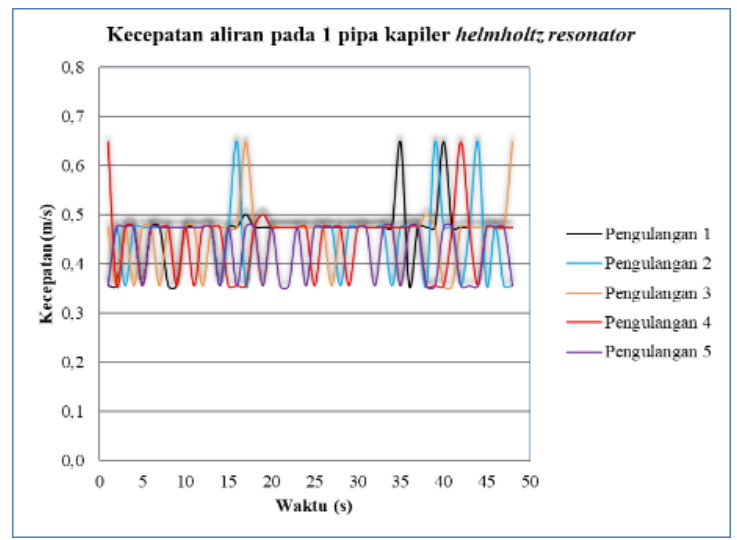

(a)

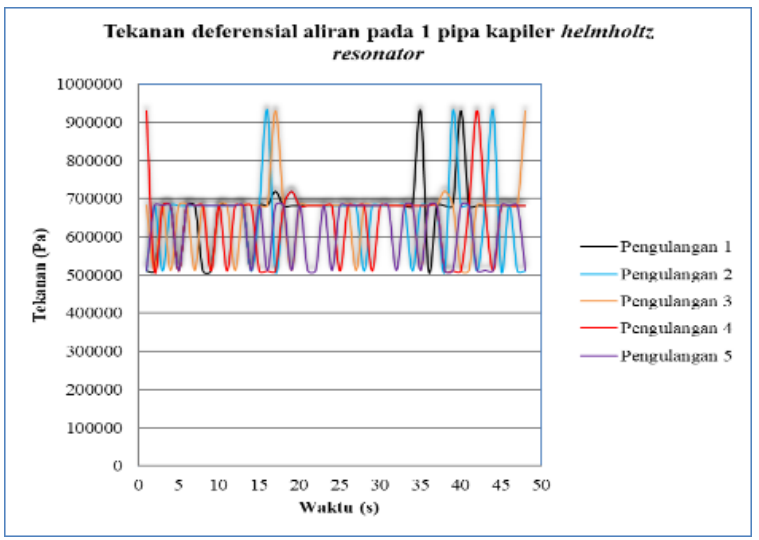

(b)

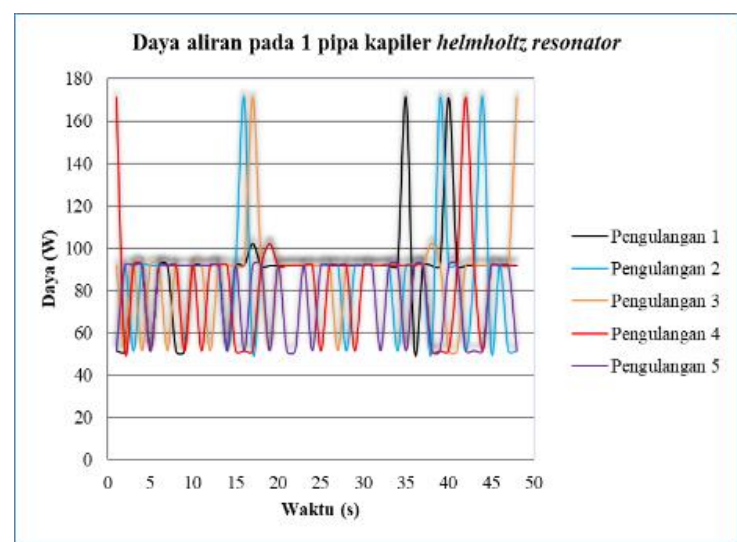

(c)

Gambar 6. Grafik percobaan 1 pipa kapiler

(a) kecepatan aliran, (b) tekanan diferensial aliran, (c) daya aliran

b. Kecepatan aliran, tekanan diferensial aliran, dan daya aliran untuk percobaan 2 pipa kapiler

Untuk percobaan dengan 2 pipa kapiler Helmholtz resonator, tercatat bahwa pada waktu 15, 40, 43, dan 44 det, kecepatan aliran sebesar $0,647924 \mathrm{~m} / \mathrm{s}$, tercapai pada pengulangan ke-1 (Gambar 7.a). Pada waktu yang sama, tekanan diferensial aliran adalah sebesar 930373,00 Pa (Gambar 7.b). Sementara, Daya aliran sebesar 170,914353 W (Gambar 7.c).

\section{c. Kecepatan aliran, tekanan diferensial aliran, dan daya aliran untuk percobaan 3 pipa kapiler}

Pada percobaan dengan 3 pipa kapiler Helmholtzresonator, kecepatan aliran pada waktu 21, 34, 40, 44 dan 48 det, adalah sebesar $0,647924 \mathrm{~m} / \mathrm{s}$, yang tercapai pada pengulangan ke-4 (Gambar 8.a). Pada waktu yang sama, tekanan diferensial aliran adalah sebesar 930373,00 Pa (Gambar 8.b),sementara, daya aliran sebesar 170,914353 W (Gambar 8.c). 


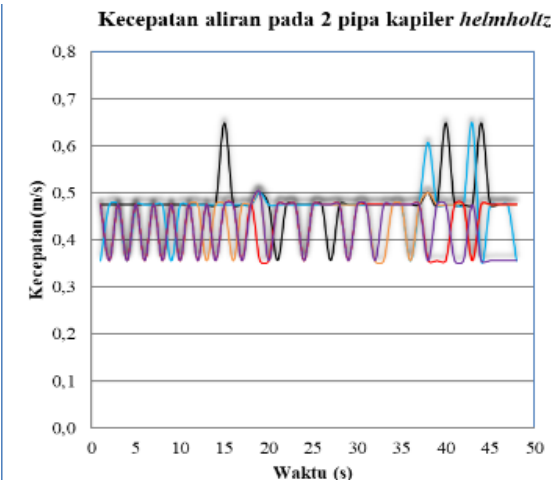

(a)

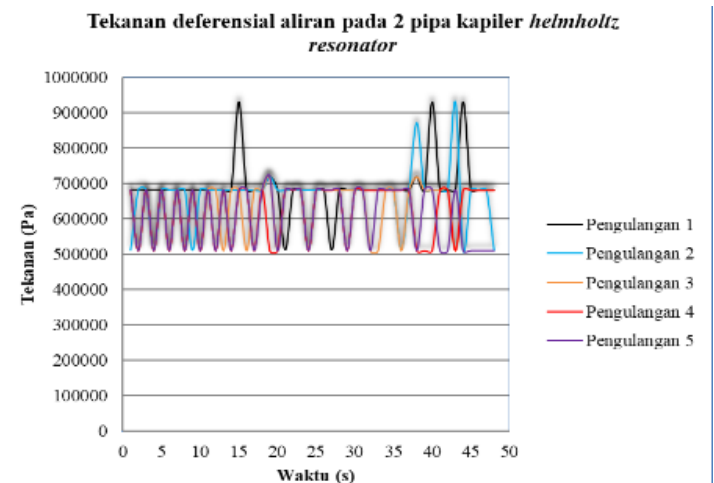

(b)

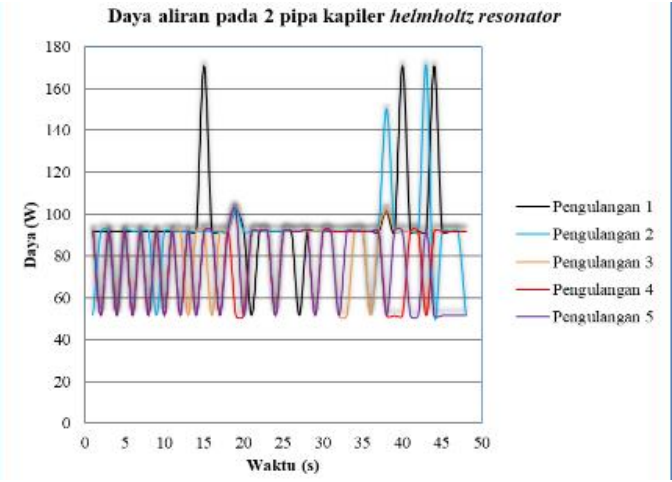

(c)

Gambar 7. Grafik percobaan 2 pipa kapiler

(a) kecepatan aliran, (b) tekanan diferensial aliran, (c) daya aliran

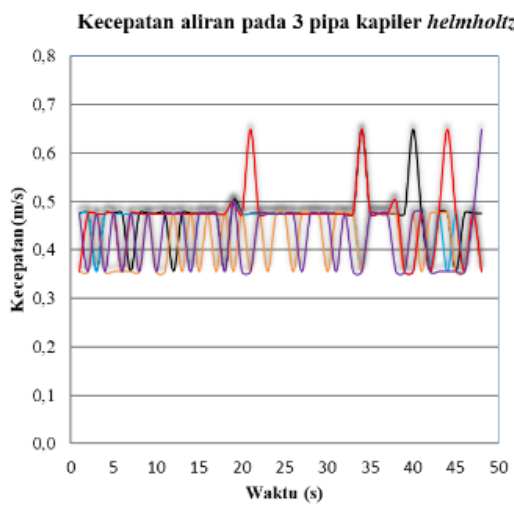

(a)

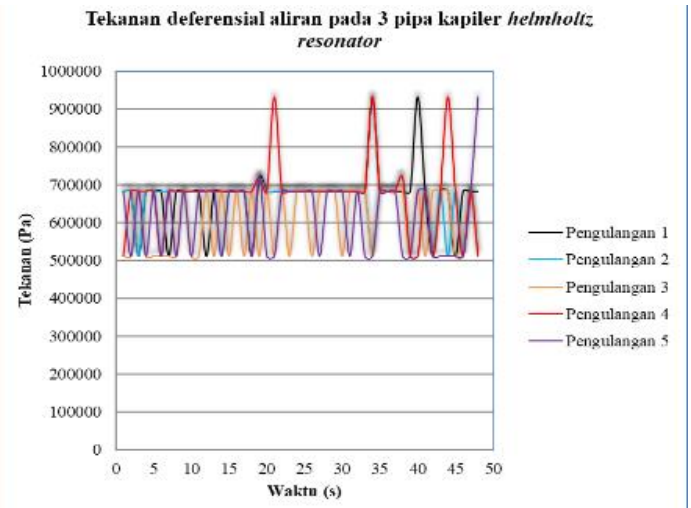

(b)

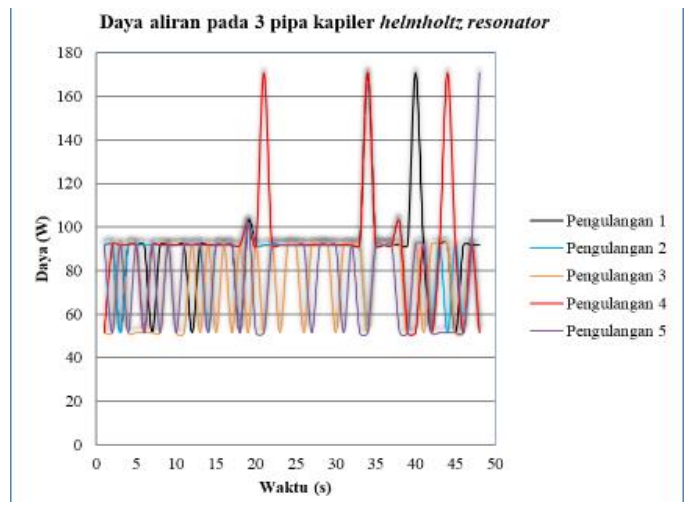

(c)

Gambar 8. Grafik percobaan 3 pipa kapiler

(a) kecepatan aliran, (b) tekanan diferensial aliran, (c) daya aliran 


\section{d. Kecepatan aliran, tekanan diferensial aliran, dan daya aliran untuk percobaan 4 pipa kapiler}

Untuk percobaan dengan 4 pipa kapiler helmholtz resonator, pada waktu 4, 9, 14, 24, 29, $35,41,42,43,45$, dan 47 det, kecepatan aliran sebesar $0,647924 \mathrm{~m} / \mathrm{s}$, tercapai pada pengulangan ke-3 (Gambar 9.a). Tekanan diferensial aliran sebesar 930373,00 Pa (Gambar 9.b), dan daya aliran sebesar 170,914353 W, tercapai pada pengulangan ke-3 (Gambar 9.c).

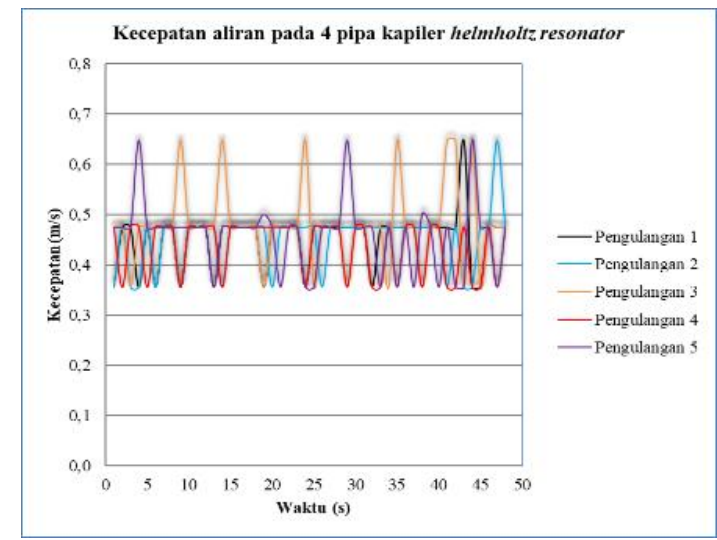

(a)

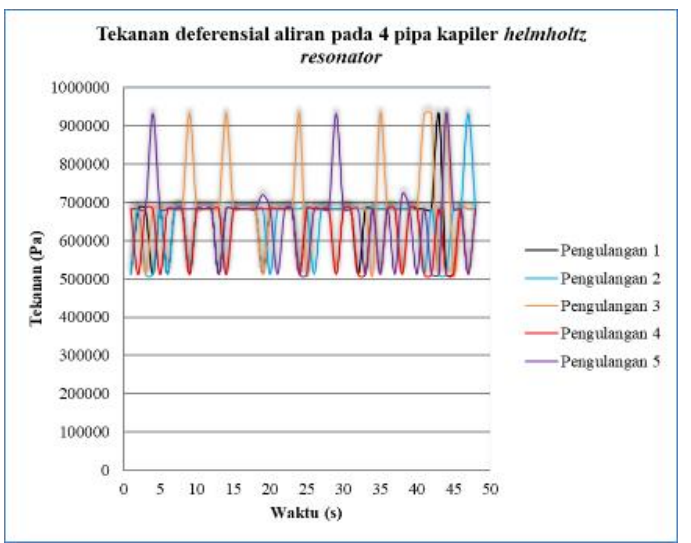

(b)

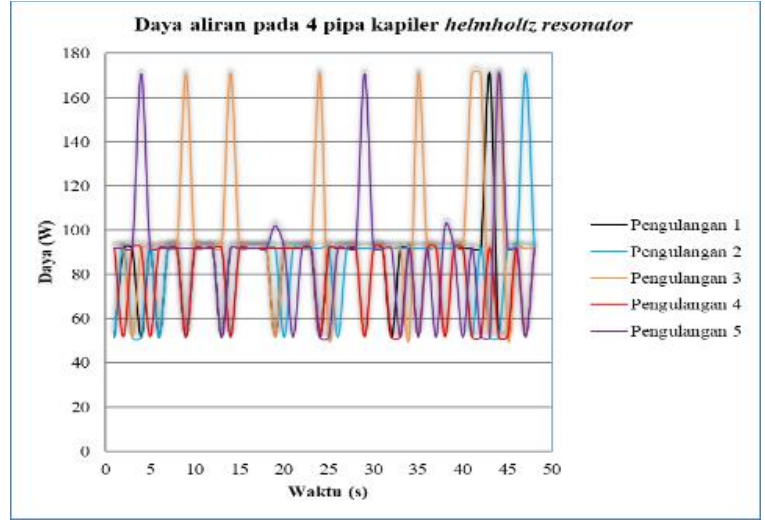

(c)

Gambar 9. Grafik percobaan 4 pipa kapiler

(a) kecepatan aliran, (b) tekanan diferensial aliran, (c) daya aliran

e. Kecepatan aliran, tekanan diferensial aliran, dan daya aliran untuk percobaan 5 pipa kapiler

Untuk percobaan dengan 5 pipa kapiler helmholtz resonator, pada waktu 26, dan 48 det, kecepatan aliran adalah sebesar 0,647924 m/s, tercapai pada pengulangan ke-1 (Gambar 10.a), tekanan diferensial aliran sebesar 930373,00 $\mathrm{Pa}$ (Gambar 10.b) dan daya aliran sebesar 170,914353 W (Gambar 10.c).

\section{f. Pembahasan}

Berdasarkan hasil pengolahan data maka terlihat bahwa debit minimum dari perlakuan ke 1, 2, 3 dan 4 adalah $0,000102 \mathrm{~m}^{3} / \mathrm{s}$, nilai kecepatan minimum $1,624310 \mathrm{~m} / \mathrm{s}$, tekanan minimum $511525,02 \mathrm{~Pa}$, dan daya minimum sebesar $51,665198 \mathrm{~W}$, sementara untuk perlakuan ke 5 debit minimumnya $0,000079 \mathrm{~m} 3 / \mathrm{s}$, nilai kecepatan minimum $0,275405 \mathrm{~m} / \mathrm{s}$, tekanan minimum $395426,25 \mathrm{~Pa}$, dan daya alir minimum 30,879794 W.Pada grafik kecepatan, tekanan dan daya untuk kelima perlakuan terlihat bahwa:

1. Perlakuan pada 1 pipa kapiler helmholtz resonator pada pengulangan ke-4tercapai kecepatan maksimum 0,647924 m/s, tekanan maksimum 930373,00 Pa, dan untuk daya alir maksimum sebesar 170,914353 W. 


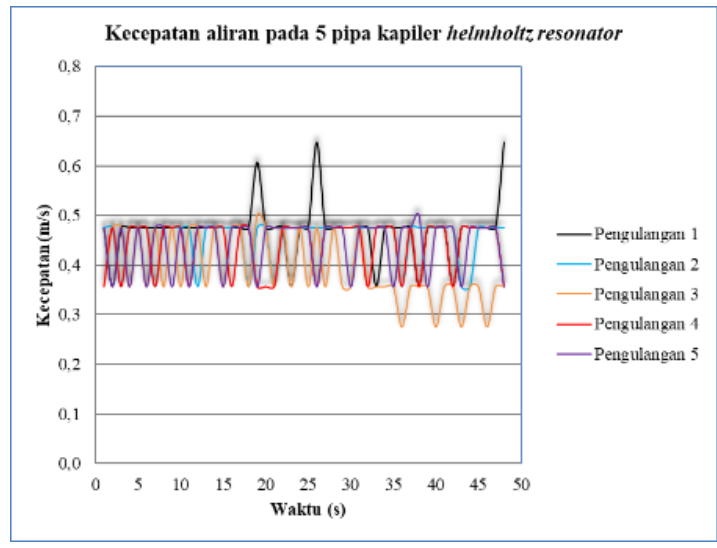

(a)

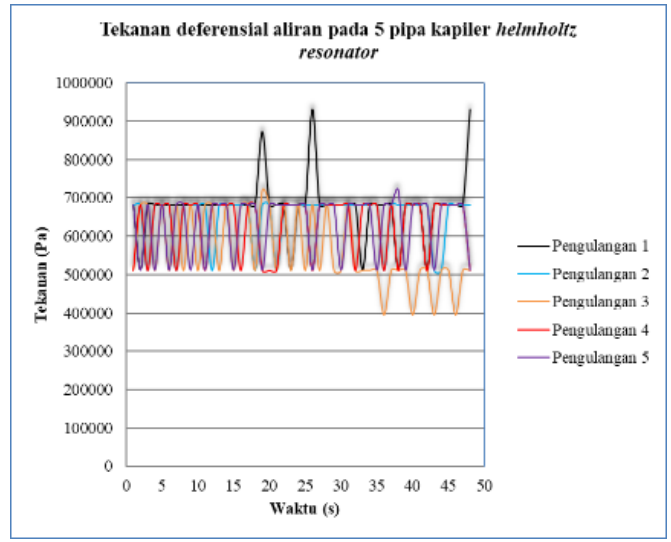

(b)

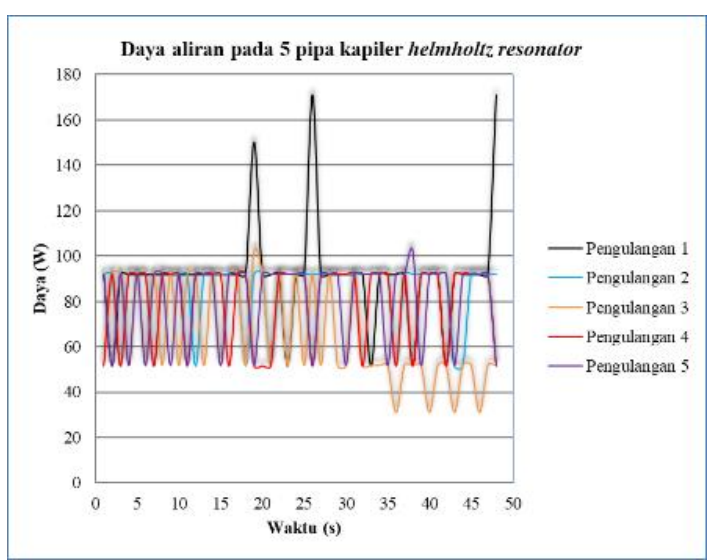

(c)

Gambar 10. Grafik percobaan 5 pipa kapiler

(a) kecepatan aliran, (b) tekanan diferensial aliran, (c) daya aliran

2. Perlakuanpada 2 pipa kapiler helmholtz resonator pada pengulangan ke-1tercapai kecepatan maksimum 0,647924 m/s, tekanan maksimum 930373,00 Pa, dan untuk daya alir maksimum sebesar 170,914353 W.

3. Perlakuan pada 3 pipa kapiler helmholtz resonator pada pengulangan ke-4tercapai kecepatan maksimum 0,647924 m/s, tekanan maksimum 930373,00 Pa, dan untuk daya alir maksimum sebesar 170,914353 W.

4. Perlakuan pada 4 pipa kapiler helmholtz resonator pada pengulangan ke-3tercapai kecepatan maksimum 0,647924 m/s, tekanan maksimum 930373,00 Pa, dan untuk daya alir maksimum sebesar 170,914353 W.

5. Perlakuanpada 5 pipa kapiler helmholtz resonator pada pengulangan ke-1tercapai kecepatan maksimum 0,647924 m/s, tekanan maksimum 930373,00 $\mathrm{Pa}$, dan untukdaya alir maksimum sebesar 170,914353 W.

Sehingga disimpulkan kecepatan,tekanan dan daya aliran fluida terbaik pada variasi empat pipa kapiler dengan waktu 4, 9, 14, 24, 29, 35, 41, 42, 43, 45 dan 47 secon sedangkan pada variasi lima pipa kapiler tidak di rekomendasikan.

\section{KESIMPULAN}

Hasil penelitian ini menunjukan bahwa setiap perlakuan mengalami peningkatan daya alir fluida setelah diffuser. Daya alir fluida setelah diffuser yang terbesar berada pada helmholtz resonator dengan jumlah 4 pipa kapiler yaitu sebesar 170,914353 Watt. Dengan demikian dapat disimpulkan bahwa kinerja pompa jet-ejector dengan helmholtz resonator mengalami peningkatan sebesar $36 \%$ dari daya sebesar 125 Watt sebelum modifikasi. 


\section{DAFTAR PUSTAKA}

Arduino.com. (2016). Arduino Mega. Diakses pada tanggal 20 Oktober 2021 pukul 15.00 WIT dari https://www.arduino.cc/en/Main/arduinoBoardMega.

Bejan, A. (1984). Convection Heat Transfer, Wiley- Interscience, New York.

Bortoluzzi Daniele, Vittore Cossalter, Alberto Doria. (1998). The Effect of Tunable Resonators on The Volumetric Efficiency of An Engine. SAE technical paper series 98MSE-10 NO. 983045.

Chirstopher Earls Brennen. (1994). "Hydrodynamics of pumps"

Claywell, Mark and Donald Horkheimer. (2006). Improvement of Intake Restrictor Performance for a Formula SAE Race Car through 1D \& Coupled 1D/3D Analysis Methods. SAE 2006-01-3654.

Faris, M., Utomo, T.S., and Syaiful. 2014. Pengaruh tekanan boiler dan variasi panjang throat terhadap performa steam ejector, Jurnal Simetris, vol. 5, no. 1, pp. 57-66

Fox, Robert.W., et al (2008) "Introduction Fluid Mechanics"

Helmholtz, Hermann Ludwig Ferdinand Von (1821-1894) dalam Biografi MCN. Diperoleh pada 23 oktober 2021 dari MCN Biografi: monbiografias.com

Hesketh, R.P., Fraser Russel, T. W., and Etchell, A.W. 1987. "Bubble Size in Horizontal Pipelines," AlChE Journal, Vol 33, No. 4.

Ishii, M. and Mishima, K., (1984). "Two-Fluid Model and Hydrodynamic Constitutive Relations" Nuclear Engineering and Design 82, pp 107-126.

Kolmogorov, A.N., (1949). Doklady Akad. Nauk., SSSR, Vol 66, 825,

Kornhauser, A.A, Bunch, T.K., And ., M. p (1996). "Efficiency of a Flashing Flow Nozzle" Proceedings of the 31st Intersociety Energy Conversion EngineeringConference.

Louhenapessy, K. (2017). Studi Eksperimental Pengaruh Pipa Kapiler Helmholtz Resonator Terhadap Tekanan Aliran Udara Supercharging-Aftercooler Pada Inlet Manifold. Ambon.

Rompis S. Y. R. (2012), "Traffic Flow Model and Shockwave Analysis", Old Dominion University Civil And Environmental Engineering.

Ruang Trakroon, N., aphorntratana, S., Sriveerakul, T.., (2011). Experimental studies of a steam jet refrigeration cycle : effect of the primary nozzle geometries to system performance. Thermal and Fluid Science, ELSEVIER

Wan, D. A. (2004). "Two Degrees of Freedom Helmholtz Resonator Analysis".

White F.M. (1991), "Fluid Mechanics", 2th edition, New York, United States of America, McGraw-Hill.

Xioafeng Shi, C. M. (2013). Attenuation Performance of A Semi-Active Helmholtz Resonator In a Grazing Flow Duct. Journal of Acoustics., 25-29

Yuanita.F.A, dkk, (2019). Pengaruh Diameter Leher Resonator Helmholtz Pada Alat Pemanen Energi Akustik (Acoustic Energy Harvester) Terhadap Daya Listrik Yang Dihasilkan. Prosiding SNFA, E-ISSN: 2548-8325 